\title{
Assessment of voluntary rhythmic muscle contraction-induced exercising blood flow variability measured by Doppler ultrasound
}

\author{
Takuya Osada ${ }^{1,2 *}$, Bengt Saltin ${ }^{2}$, Göran Rådegran ${ }^{2,3,4}$ \\ ${ }^{1}$ Department of Sports Medicine for Health Promotion, Tokyo Medical University, Tokyo, Japan \\ ${ }^{2}$ The Copenhagen Muscle Research Centre, Rigshospitalet, University of Copenhagen, Copenhagen, Denmark \\ ${ }^{3}$ The Clinic for Heart Failure and Valvular Disease, Skåne University Hospital, Lund, Sweden \\ ${ }^{4}$ Department of Cardiology, Clinical Sciences, Lund University, Lund, Sweden \\ Email: ${ }^{\text {DENTACMAC@aol.com }}$
}

Received 25 September 2013; revised 25 October 2013; accepted 2 November 2013

Copyright (C) 2013 Takuya Osada et al. This is an open access article distributed under the Creative Commons Attribution License, which permits unrestricted use, distribution, and reproduction in any medium, provided the original work is properly cited.

\section{ABSTRACT}

Given recent technological developments, ultrasound Doppler can provide valuable measurements of blood velocity/flow in the conduit artery with high temporal resolution. In human-applied science such as exercise physiology, hemodynamic measurements in the conduit artery is commonly performed by blood flow feeding the exercising muscle, as the increase in oxygen uptake (calculated as a product of arterial blood flow to the exercising limb and the arterio-venous oxygen difference) is directly proportional to the work performed. The increased oxygen demand with physical activity is met through a central mechanism, an increase in cardiac output and blood pressure, as well as a peripheral mechanism, an increase in vascular conductance and oxygen extraction (a major part of the whole exercising muscles) from the blood. The increase in exercising muscle blood flow in relation to the target workload (quantitative response) may be one indicator in circulatory adjustment for the activity of muscle metabolism. Therefore, the determination of local blood flow dynamics (potential oxygen supply) feeding repeated (rhythmic) muscle contractions can contribute to the understanding of the factors limiting work capacity including, for instance, muscle metabolism, substance utilization and magnitude of vasodilatation in the exercising muscle. Using non-invasive measures of pulsed Doppler ultrasound, the validity of blood velocity/flow in the forearm or lower limb conduit artery feeding to the muscle has been previously demonstrated during rhythmic muscle exercise. For the evaluation of exercising blood

\footnotetext{
${ }^{*}$ Corresponding author.
}

flow, not only muscle contraction induced internal physiological variability, or fluctuations in the magnitude of blood velocity due to spontaneous muscle contraction and relaxation induced changes in force curve intensity, superimposed in cardiac beat-by-beat, but also the alterations in the blood velocity (external variability) due to a temporary sudden change in the achieved workload, compared to the target workload, should be considered. Furthermore, a small amount of inconsistency in the voluntary muscle contraction force at each kick seems to be unavoidable, and may influence exercising muscle blood flow, although subjects attempt to perform precisely similar repeated voluntary muscle contractions at target workload (muscle contraction force). This review presents the methodological considerations for the variability of exercising blood velocity/flow in the limb conduit artery during dynamic leg exercise assessed by pulsed Doppler ultrasound in relation to data previously reported in original research.

Keywords: Exercising Blood Flow; Doppler Ultrasound; Muscle Contraction; Blood Flow Alterations

\section{INTRODUCTION}

In integrated and applied human physiology, blood flow plays a key role, as oxygen transport via blood flow to the working muscles is crucial for exercise capacity. Furthermore, the magnitude of blood flow in the exercising muscle may also be related to the blood volume redistribution, via systemic circulation, as seen in previous studies focused on cardiovascular regulation in humans $[1,2]$. The oxygen uptake is evaluated by the product of 
cardiac output and arterio-venous oxygen concentration difference. Consequently peripheral conduit arterial blood flow to the working muscle is one indicator of the metabolic demand in local large muscle groups [3]. Moreover, detecting utilization in the leg requires comprehensive leg blood flow and arterio-venous substance concentration difference $[4,5]$.

Peripheral circulatory changes during exercise correspond to the stress imposed on the cardiovascular system [6,7]. Cardiac output increases with increasing exercise intensity along with enhanced skeletal muscle vasodilatation and muscle pumping in the exercising muscle. As the perfusion in the active muscle is one further indicator of oxygen delivery to the muscles, blood velocity and flow in the feeding conduit arteries to working skeletal muscle may also give valuable information regarding the hemodynamic response to exercise (particularly for large muscle groups in the upper or lower limbs).

Recent advanced ultrasound Doppler instruments can provide valuable measurements of arterial blood flow with high temporal resolution in the cardiovascular system. The determination of blood velocity in the feeding conduit artery at rest and during rhythmic muscle contractions during exercise has an impact on transient changes in hemodynamics $[6,8,9]$. The investigation of the blood flow supply due to continuous muscle contractions may require the evaluation of the effect of physical activity on regulation among central and peripheral hemodynamics.

Since one of the advantages of Doppler ultrasound is that it can provide an evaluation of high temporal resolution blood velocity, the oscillation of blood velocity may be detected at rest as a measure of heart beat and blood pressure. During repeated muscle contractions of exercise, these oscillations are even more pronounced, as they are also influenced by intramuscular pressure variations. Therefore, the measurement of valid blood velocity should be done carefully to account for the influence of changes in the voluntary muscle contraction force in inducing physiological blood velocity fluctuation (internal variability), as well as the alterations in the blood velocity (external variability) due to a temporary sudden change in the achieved workload compared to the target workload.

Acknowledging the above mentioned variability in the conduit arterial blood velocity, feeding into voluntary rhythmic muscle contractions is valuable information for the determination of exercising blood flow under various muscle contraction intensities. The purpose of the present review is therefore to summarize the physiological considerations of the variability of the exercising blood velocity/flow in the limb conduit artery during thigh muscle kicking exercise (dynamic knee extensor exercise model) assessed by Doppler ultrasound.
The paper is organized as follows: 1) Muscle contraction-induced physiological (internal) variations in blood velocity during rhythmic muscle contractions, 2) Validation of exercising blood flow during rhythmic muscle contractions and 3) Changes in exercising blood flow (external variations) due to spontaneous changes of muscle contraction force (workload) compared to target intensity.

\section{METHODOLOGICAL CONSIDERATIONS}

\subsection{Exercise Model}

Determinations of blood flow to contractile muscles are the primary focus of the present review. Whole body exercise methods such as walking and running on a treadmill do not easily allow measurement of upper- and lower-limb blood flow using Doppler ultrasound as motion artifacts are present. There is also difficulty in fixing the ultrasound Doppler probe. Whole lower limb muscle blood flow may be measured using the one-legged, repeated kicking (dynamic knee-extensor) exercise model described by Andersen and Saltin [10]. In this exercise model, the subject performs leg kicking while the leg is passively returned by the cycle ergometer. Consequently, the work is confined to the quadriceps muscle group and the model allows stable measurements of femoral arterial blood velocity using Doppler ultrasound because the subject is seated (Figure 1). Therefore, all hemodynamic data described in this review are from one-legged repeated kicking (dynamic knee-extensor) exercise with the activation of the large thigh muscle group.

\subsection{Hemodynamic Measurements}

Ultrasound instrumentation: The measurements were performed using a Doppler ultrasound instrument (Model CFM 800, Vingmed Sound, Horten, Norway) equipped with an annular phased array transducer (Vingmed Sound) probe (11.5-mm diameter). The imaging frequency was $7.5 \mathrm{MHz}$ and the Doppler frequencies varied between 4.0 and $6.0 \mathrm{MHz}$ (high-pulsed repetition frequency mode, 4 - $36 \mathrm{kHz}$ ). Blood velocity was measured

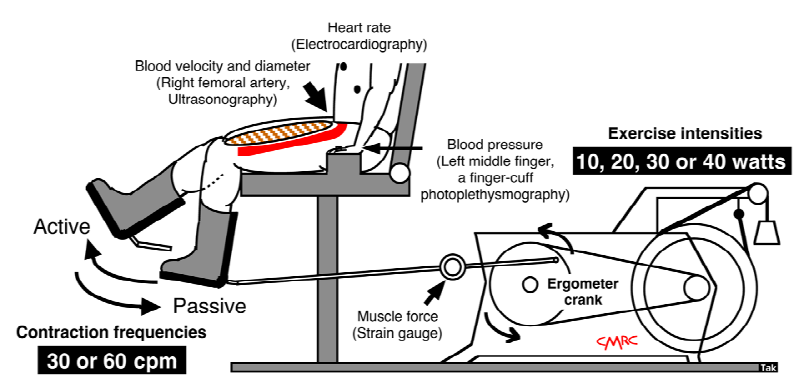

Figure 1. One-legged dynamic kicking (knee extensor) exercise as a model of rhythmic thigh muscle contractions. 
with the probe at the lowest possible insonation angle and always $<60^{\circ}[11]$. The mean value of the insonation angle was $\sim 50^{\circ}$, which remained constant throughout the experiments for each individual. The probe position was stable and the sample volume was precisely positioned in the center of the vessel and adjusted to cover the diameter width of the vessel.

Blood velocity, vessel diameter and blood flow: The measurements of blood velocity and blood flow in the femoral artery using Doppler ultrasound has previously been validated and shown to produce accurate absolute values both at rest and during leg exercise such as rhythmical thigh muscle contractions $[6,8,9,12,13]$. Compared with thermodilution, the high temporal resolution of pulsed Doppler ultrasound additionally enables continuous measurement of blood velocity throughout the knee-extensor exercise [6-9,14,15].

The angle-corrected, time and space-averaged, and amplitude-weighted mean blood velocities were measured. Mean blood velocity was defined by averaging the mean blood velocity trace, including both negative and positive values [6,7]. The blood velocity parameter was measured in relation to the blood pressure curve. The site of blood velocity and vessel diameter measurements in the femoral artery was distal to the inguinal ligament but above the bifurcation into the branch of the superficial and deep femoral artery. This location minimizes turbulence from the femoral bifurcation and the influence of blood flow from the inguinal region. In addition, the arterial diameter is not affected by the contractions and relaxations at this site, located proximal to the muscle.

The blood velocity measurements were performed when steady-state had been reached after $3 \mathrm{~min}$ of onelegged, dynamic knee extensor exercise, as previously described $[6,13,14]$. The systolic and diastolic diameters of the femoral artery were measured on a monitor relative to the electromyography at rest. The mean vessel diameter was calculated in relation to the temporal duration of the blood pressure curve as; [(systolic vessel diameter value $\times 1 / 3)+($ diastolic vessel diameter value $\times$ 2/3)] [6]. The diameters were measured under perpendicular insonation at rest before exercise. The value of the vessel diameter at rest (pre-exercise) was used to calculate femoral arterial blood flow during rest and during one-legged, dynamic knee extensor exercise, since the diameter does not vary between rest and steadystate exercise $[1,6,12,16-18]$. Steady-state one-legged blood flow was calculated by multiplying the cross-sectional area $\left[\right.$ Area $\left.=\pi \times(\text { vessel diameter } / 2)^{2}\right]$ of the femoral artery, with the angle corrected, time and spaceaveraged, and amplitude (signal intensity) weighted mean-blood velocity, where blood flow = mean-blood velocity $\times$ cross-sectional area. Thus, the changes in blood flow dynamics were basically parallel to the changes in blood velocity.

Muscle force and work rate: Kicking muscle force was measured using a strain gauge. Variations in muscle force were taken to represent oscillations in intramuscular pressure, as these parameters have been shown to temporally correlate closely to each other during dynamic knee extensor exercise $[6,14,19]$. The external workload (work rate) was calculated according to the knee extensor ergometer model [10,20], defined as: external workload $(\mathrm{watt})=[$ contraction frequency $($ contraction per minute, $\mathrm{cpm}) / 60 \mathrm{~s}] \times[$ distance of one knee extensor revolution $(6 \mathrm{~m})] \times\left[\mathrm{load}(\mathrm{kg}) \times 9.81\left(\mathrm{~m} / \mathrm{s}^{2}\right)\right]$. The specific loads applied were $0.333,0.667,1.0$ and 1.333 $\mathrm{kg}$ at 10, 20, 30 and 40 watt, respectively, at $30 \mathrm{cpm}$; and $0.167,0.333,0.5$ and $0.667 \mathrm{~kg}$ at $10,20,30$ and $40 \mathrm{watt}$ at $60 \mathrm{cpm}$.

The external workload was evaluated by integrating delta $\mathrm{dP}$ during the muscle contraction phase, where $\mathrm{dP}$ (to time integral) $=\mathrm{dF}[\mathrm{N}] \mathrm{i} \times \mathrm{R} \times \mathrm{Sin}[$ alpha $] \mathrm{i} \times$ revolution per minute/60, were determined for each knee extensor kicking session. The external workload $=$ integral of $\mathrm{dP}$ from time integral $=0($ where alpha $=0)$ to time integral $=\mathrm{x}($ where alpha $=\mathrm{pi}) ; \mathrm{dF}[\mathrm{N}] \mathrm{i}$, force (in Newtons) on the kicking arm transducer to time integral; R, Length of pedal arm in meters; Sin[alpha]i, Sin to horizontal angle to time integral; revolution per minute, actual angular velocity in rounds per minute to time integral; and "dF[N]i $\times \mathrm{R} \times \operatorname{Sin}[$ alpha]i" is the delta torque $[\mathrm{Nm}]$ to time integral. The achieved workload determined by this method was displayed in real time on a monitor visible to the subjects, to maintain the target workload during dynamic knee extensor exercise.

\section{EVALUATION OF EXERCISING MUSCLE BLOOD FLOW}

\subsection{Muscle Contraction-Induced Physiological Variations in Blood Velocity during Rhythmic Muscle Contractions}

Continuous recordings can clearly determine the magnitude of the physiological variability in blood velocity by the contraction-relaxation-induced variations in muscle force, and consequently the intramuscular pressure variations, along with the superimposed influence of the blood pressure, as well as the tonic influence of the state of vasodilatation $[6,13,21]$. The high intramuscular pressure during muscle contractions may consequently temporarily reduce or even reverse the blood velocity, depending on the relationship between the intramuscular- and arterial blood pressure. The major extent of the blood velocity and flow consequently occurs during the muscle relaxation phase $[6,13,22]$. Blood velocity fluctuated in relation to the state of vasodilatation and the muscle contraction-relaxation duty cycles, indicated by the oscilla- 
tions in muscle force.

In general, the blood velocity increased to its highest value at the systolic blood pressure phase during muscle relaxation, and significantly decreased to its lowest value at the diastolic blood pressure phase during muscle contraction (Figure 2). The blood velocity showed an intermediate value at the systolic blood pressure phase during muscle contraction and at the diastolic blood pressure phase during muscle relaxation, respectively. The blood velocity curve was furthermore retrograde in the diastolic blood pressure phase during muscle contraction.

In Figure 3, the limited view of blood velocity profile in relation to single muscle contraction-relaxation and single cardio systolic-diastolic beat, as well as the blood velocities during the systolic and diastolic phases were found continuously in parallel with the blood pressure curve during the muscle contraction and muscle relaxation phases determined from the electromyography and the muscle force curve.

Four variations in the coupling between the blood

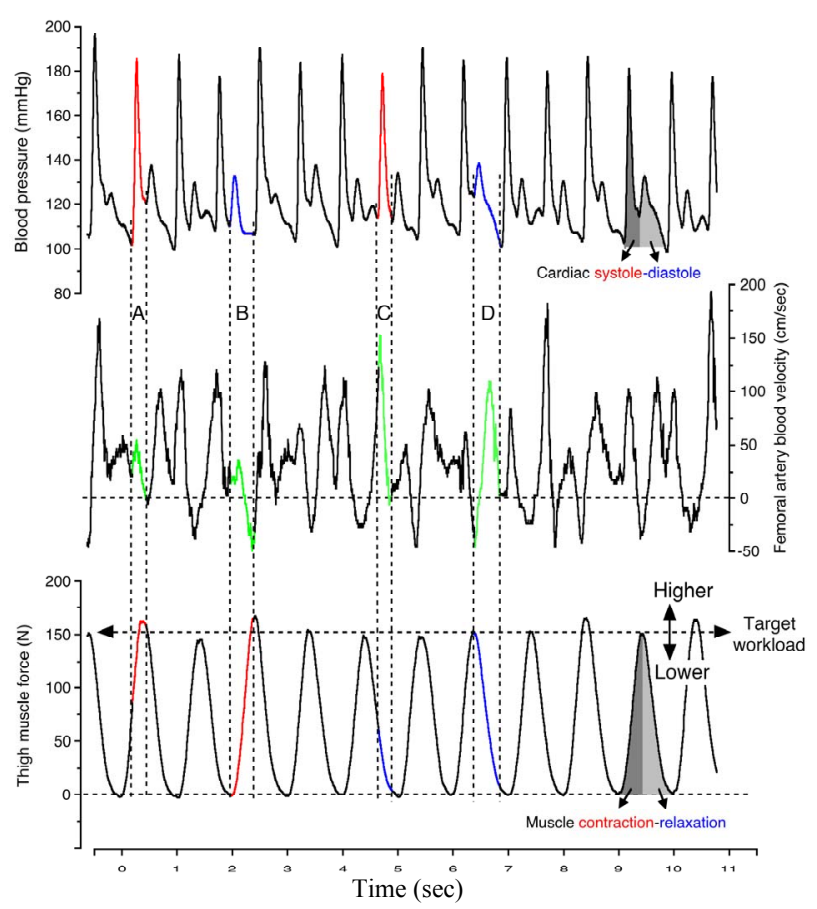

Figure 2. Continuous recording of blood velocity in the femoral artery, blood pressure and thigh muscle force during steady-state one-legged dynamic kicking (knee extensor) exercise at 20 watts and 60 contractions per minute. The letters depicted indicate; A: Muscle contraction at systolic blood pressure phase, B: Muscle contraction at diastolic blood pressure phase, C: Muscle relaxation at systolic blood pressure phase, D: Muscle relaxation at diastolic blood pressure phase. During rhythmic exercise, the peak thigh muscle force was seen over or under target work load. The higher or lower achieved muscle force (workload) may influence blood flow values in Figures 5 and 6. Figure adapted from Osada and Rådegran [21], reproduced with permission from Edizioni Minerva Medica.

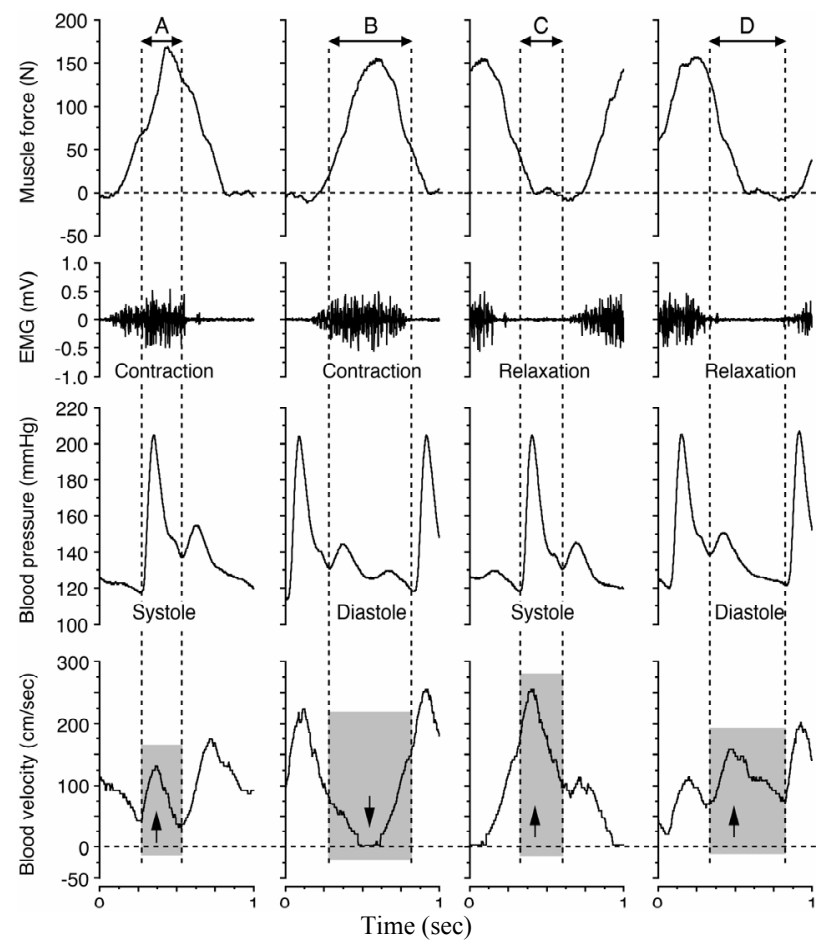

Figure 3. Blood velocity profile for the systolic and diastolic phases during the muscle contraction and muscle relaxation phases at 20 watts and 60 contractions per minute. The arrows down and up indicate the influence of the blood velocity, depending on the magnitude of, and temporal relation between, the muscle force ( $\approx$ intramuscular pressure), the electromyography (EMG) and the blood pressure, respectively. These panels (A-D) are expanded by the part of blood velocity profile corresponding to them in Figure 2. Figure adapted from Osada and Rådegran [22], reproduced with permission from The Physiological Society of Japan.

pressure curve and the state of muscle contraction and relaxation were indicated; the systolic phase during muscle contraction, the diastolic phase during muscle contraction, the systolic phase during muscle relaxation, and the diastolic phase during muscle relaxation. The formation of the blood velocity profile and flow was influenced by the intramuscular pressure, as indicated by the muscle force curve, and the superimposed influence of blood pressure in relation to the systolic and diastolic phases. The magnitude of blood flow value measured against the 4 variations indicates the large difference in work rates during the muscle relaxation phase and those of the muscle contraction phase at systolic and diastolic points, respectively.

\subsection{Validation of Exercising Blood Flow during Rhythmic Muscle Contractions}

In previous reports, peripheral hemodynamic measurements have been performed using the thermodilution technique for leg blood flow during dynamic knee-extensor exercise [10]. However, this invasive technique 
has the limitation of poor time resolution of blood flow. Several other techniques have previously been developed that enable estimates to be made of arterial inflow, venous outflow, and local blood flow within a muscle [23-29]. Whereas many of the techniques are impaired by different methodological limitations, the indicator thermodilution and the ultrasound Doppler method have both been found to give repeatable measurements of the same magnitude during both rest and dynamic knee extensor exercise [6,30] (Figure 4).

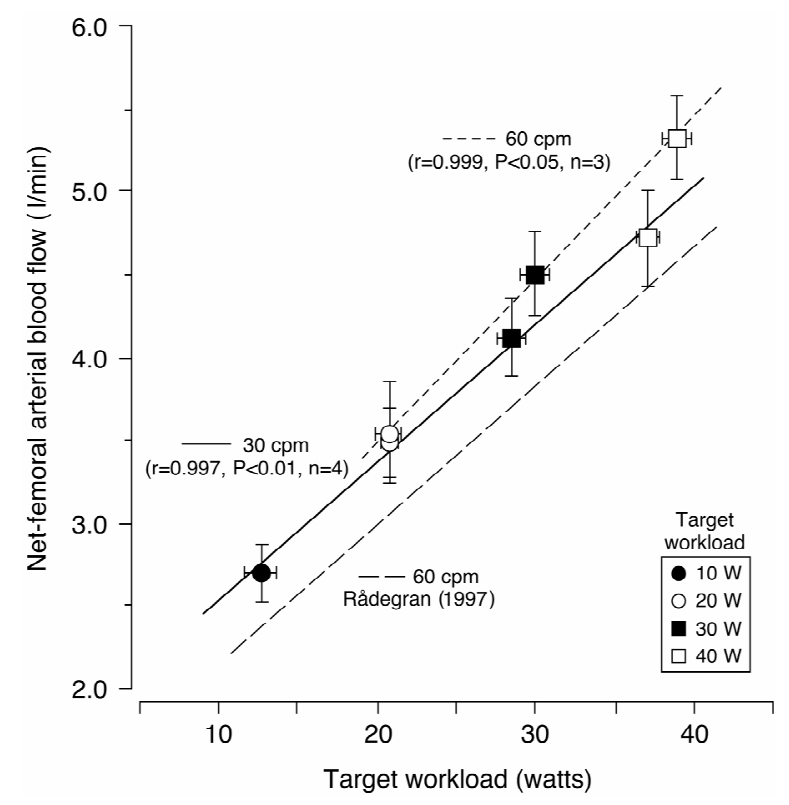

Figure 4. Relationship between net-femoral arterial blood flow (FBF) and target workload during dynamic knee extensor exercise. The relationship between FBF and target workload was positive and linear at $30 \mathrm{cpm}(\mathrm{r}=0.997, \mathrm{P}<$ $0.01, \mathrm{n}=4)$ and $60 \mathrm{cpm}(\mathrm{r}=0.999, \mathrm{P}<0.05, \mathrm{n}=3)$, respectively. The value of FBF for one subject was the average value of 60 samplings at each session. Furthermore, the target workload value in each individual subject was determined by averaging values of 60 samplings of the achieved workloads at each session. Both FBF and target workload were obtained from average values of all 9 subjects. Regression equations are indicated as follows: FBF $(1 / \mathrm{min})=$ $1.71+0.083 \times$ target workload at $30 \mathrm{cpm}$ (solid line): FBF $(1 / \mathrm{min})=1.52+0.098 \times$ target workload at $60 \mathrm{cpm}$ (short dotted line). These data are in close agreement with the findings of Rådegran [6]: $\mathrm{FBF}(1 / \mathrm{min})=1.317+0.084 \times$ target workload at $60 \mathrm{cpm}$, long dotted line. The difference in absolute FBF was approximately $0.5 \mathrm{l} / \mathrm{min}$ between the present FBF data and previous reports at $60 \mathrm{cpm}$ by Rådegran [6]. This difference may be due to the subjects' characteristics, such as muscle strength variations and that they worked at different percentages of the maximum voluntary knee contraction force. However, the slope of the regression line in the present study is similar to previous findings. cpm, contractions per minute. Data are expressed as means \pm standard error. Figure adapted from Osada and Rådegran [32], reproduced with permission from John Wiley \& Sons Ltd.
There is a positive linear relationship between leg blood flow in femoral artery and target work rate $(10,20$, 30 and 40 watts) in relation to rhythmic thigh muscle contractions at 30 and 60 contractions per minute (Figure 4). With the rapid increase in energy requirements during exercise, equally rapid circulatory adjustments are essential in order to meet the increased need for oxygen and nutrients by the exercising muscle. In addition, thermodilution blood flow measurements obtained under similar experimental conditions by Andersen and Saltin [10] are closely related to those obtained by Doppler ultrasound. Thus, blood flow measured by Doppler ultrasound is valid not only at rest but also during incremental one-legged dynamic knee extensor exercise.

The Doppler technique can be used to differentiate between physiological and methodological variations in flow, as well as detect rapid changes in flow induced by exercise (dynamic or static), different metabolic states (muscle contraction intensity or frequency), or any other type of vasodilatation such as the reperfusion period after arterial occlusion or infusion of a vasodilator substance.

\subsection{Changes in Blood Flow Due to Spontaneous Changes of Workload}

Femoral arterial blood flow during steady-state rhythmic thigh muscle contractions increases linearly with incremental target workloads (work rates) [6,7,9,12,31]. This implies that enhanced vasodilatation is elicited in relation to the increased average muscle force, exerted at higher workloads, to meet the elevated metabolic activity (Figure 4). However, these blood flow values are a mean of steady-state exercising blood flow measurements, and temporary muscle contraction-induced blood flow variations may therefore be conveyed in the mean average blood flow value (Figure 5). For human voluntary exercise, it is of value to consider how variations in repeated muscle contractions at target muscle strength (muscle force) directly influence exercise blood flow in conduit arteries. Therefore, we have investigated whether sudden physiological and spontaneous changes in exercise rhythm, and consequently workload, temporarily alter blood flow to the working muscle [32].

The results showed that femoral arterial blood flow increased positively and linearly (dotted line) with increasing target workload. However, femoral arterial blood flow was inversely and linearly related (solid line) to the actual achieved workload, when measured over 60 consecutive contraction-relaxation cycle bouts for each target intensity at 30 and 60 contractions per minute, respectively (see in Figure 5).

Thus any sudden spontaneous increase or decrease in the achieved workload transiently altered the relationship between limb femoral arterial blood flow and the achieved workload. The influence upon the magnitude of 
limb femoral arterial blood flow, due to fluctuations in the achieved workload from the target workload was similar at target workload sessions of 30 and 60 contractions per minute, respectively. These findings indicate that a transient sudden increase in the workload during rhythmic muscle contractions more rapidly impedes femoral arterial blood flow, and that vasodilatation may be elicited to restore the intensity related steady-state limb blood flow response, in relation to the average metabolic activity (Figure 6).

This evidence may contribute to the evaluation of exercise hemodynamics for rhythmic, dynamic-isotonic exercise training, leading to exercise prescriptions (muscle contraction frequency or muscle contraction intensity) for healthy participants, as well as for patients requiring additional physical activity in a rehabilitation or clinical setting.

\section{CONCLUSION}

The detection of blood velocity with high temporal resolution in real time, at rest, and during exercise, is the advantage of using the non-invasive technique of the Doppler method. However, the enhanced alterations in

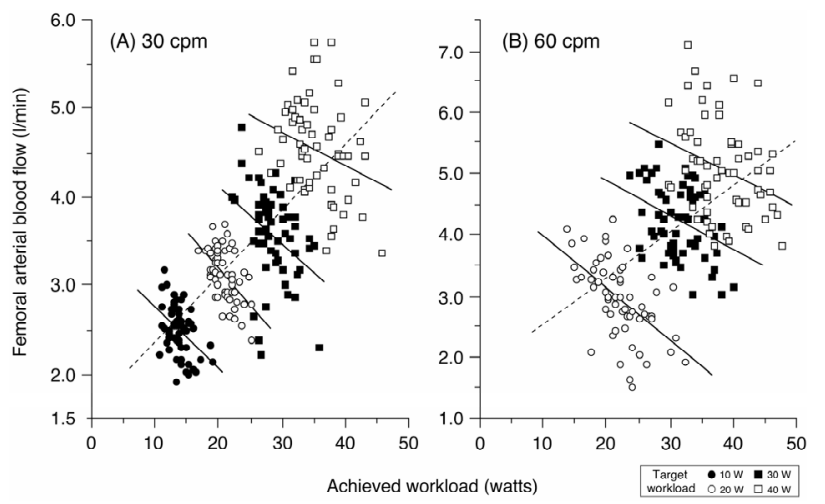

Figure 5. Relationship between steady-state femoral arterial blood flow (FBF) and the achieved workload during incremental dynamic knee-extensor exercise at 30 or 60 contractions per minute $(\mathrm{cpm})$ during a minute measurement in one subject (60 samplings at each workload). FBF was inversely related (P $<0.05$ ) to the actual achieved workload (60 samplings) at (A) 30 and (B) $60 \mathrm{cpm}$, respectively, for each target workload (solid line). The linear relationship was furthermore positive $(\mathrm{P}<$ $0.0001)$ between FBF (240 samplings at $30 \mathrm{cpm}$; 180 samplings at $60 \mathrm{cpm}$ ) and the target workloads (at 10, 20, 30 and 40 $\mathrm{W}$ at $30 \mathrm{cpm}$; and at 20,30 and $40 \mathrm{~W}$ at $60 \mathrm{cpm}$ ) in one subject (dotted line). Figure adapted from Osada and Rådegran [32], reproduced with permission from John Wiley \& Sons Ltd.

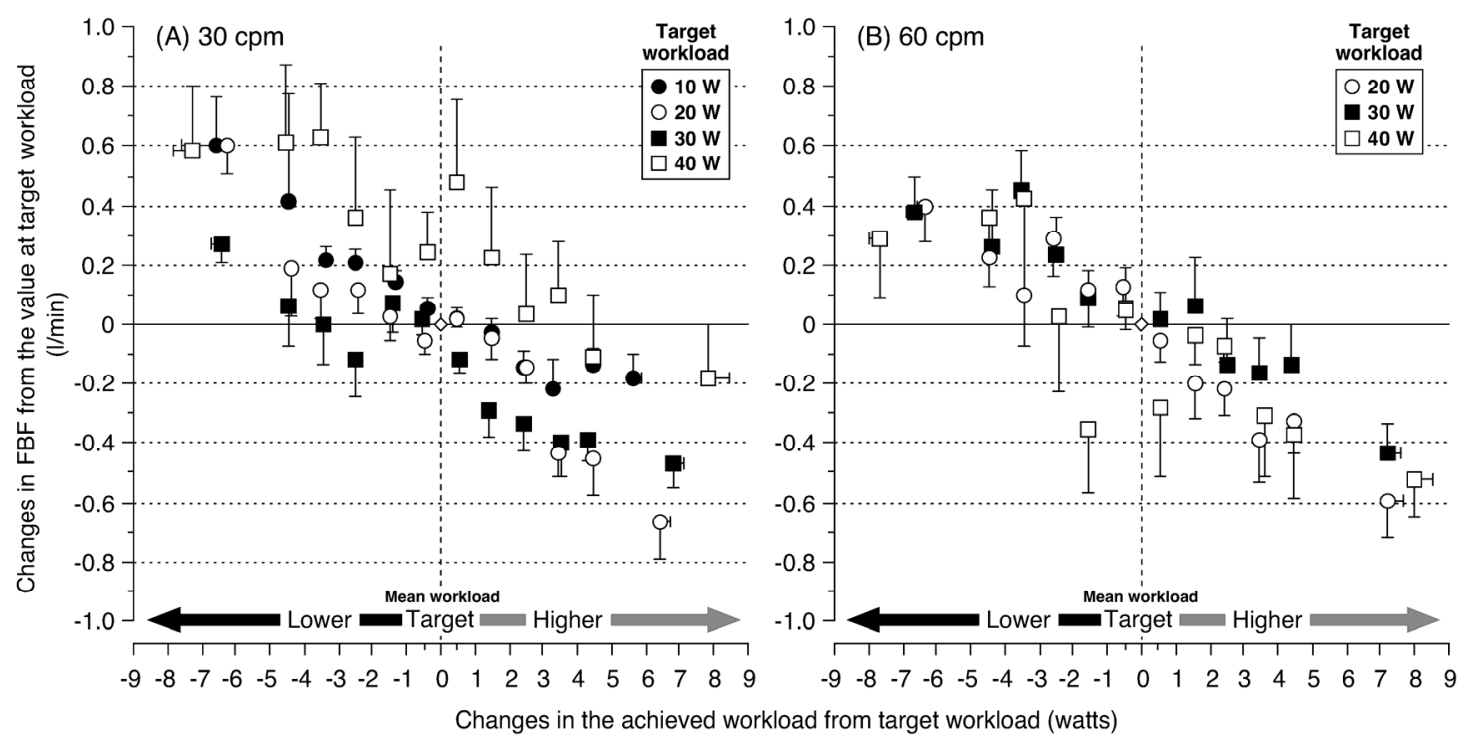

Figure 6. Changes in femoral arterial blood flow (FBF) related to fluctuations in the achieved workload around the target workload. A negative relationship was found between changes in FBF and changes in the achieved workload from mean target workload at (A) 30 and (B) 60 contractions per minute (cpm), respectively. A higher achieved workload, with a higher muscular force, reduced FBF. A lower achieved workload, with a lower muscular force, increased FBF. The influence on the FBF magnitude due to fluctuations from the target workload was similar between the target workload sessions at 30 and $60 \mathrm{cpm}$, respectively. At both 30 and $60 \mathrm{cpm}$, changes in FBF were within 0.6 and $-0.6 \mathrm{l} / \mathrm{min}$ from baseline at the target workload in all sessions. Furthermore, changes in FBF ranged between 0.2 and $-0.2 \mathrm{l} / \mathrm{min}$ from baseline when the achieved workload was increased or decreased by $\sim 2 \mathrm{~W}$. The target workload is defined as an average value (equal to mean workload) of 60 samplings for the achieved workload at each target workload $(10,20,30$, and $40 \mathrm{~W})$. The basal FBF value at the mean target workload (diamond shape) was measured as the average of the plotted FBF values between the mean target workload minus $0.5 \mathrm{~W}$ and the mean target workload plus $0.5 \mathrm{~W}$; which is defined by the horizontal standard (horizontal) line of the FBF value ("zero"). Figure adapted from Osada and Rådegran [32], reproduced with permission from John Wiley \& Sons Ltd. 
blood velocity profile may potentially confuse the evaluation of hemodynamics in the exercising muscles. This review discussed muscle contraction-induced normal physiological (internal) variations in blood velocity during rhythmic muscle contractions, as well as changes in exercising blood flow (external variations) due to spontaneous changes of muscle contraction force (workload) compared to target intensity. These findings should be considered when determining the precise physiological net-blood velocity/flow values.

\section{ACKNOWLEDGEMENTS}

The staff of The Copenhagen Muscle Research Centre is greatly acknowledged. The study was supported by the Danish National Research Foundation Grant 504-14, Uehara Memorial Foundation in 2002, a Grant-in-Aid for Young Scientists (B) in Scientific Research (No. 16700471) and the "Excellent Young Researchers Overseas Visit Program" in Scientific Research (No. 21-8285) 2010 from MEXT and JSPS.

\section{REFERENCES}

[1] Osada, T., Katsumura, T., Hamaoka, T., Inoue, S., Esaki, K., Sakamoto, A., Murase, N., Kajiyama, J., Shimomitsu, T. and Iwane, H. (1999) Reduced blood flow in abdominal viscera measured by Doppler ultrasound during onelegged knee extension. Journal of Applied Physiology, 86, 709-719.

[2] Osada, T., Iwane, H., Katsumura, T., Murase, N., Higuchi, H., Sakamoto, A., Hamaoka, T. and Shimomitsu, T. (2012) Relationship between reduced lower abdominal blood flows and heart rate in recovery following cycling exercise. Acta Physiologica, 204, 344-353. http://dx.doi.org/10.1111/j.1748-1716.2011.02349.x

[3] Saltin, B., Rådegran, G., Koskolou, M.D. and Roach, R.C. (1998) Skeletal muscle blood flow in humans and its regulation during exercise. Acta Physiologica Scandinavica, 162, 421-436.

http://dx.doi.org/10.1046/j.1365-201X.1998.0293e.x

[4] Sacchetti, M., Saltin, B., Osada, T. and Van Hall, G. (2002) Intramuscular fatty acid metabolism in contracting and non-contracting human skeletal muscle. Journal of Physiology (London), 540, 387-395. http://dx.doi.org/10.1113/jphysiol.2001.013912

[5] Steensberg, A., Febbraio, M.A., Osada, T., Schjerling, P., Van Hall, G., Saltin, B. and Pedersen, B.K. (2001) Interleukin-6 production in contracting human skeletal muscle is influenced by pre-exercise muscle glycogen content. Journal of Physiology (London), 537, 633-639. http://dx.doi.org/10.1111/j.1469-7793.2001.00633.x

[6] Rådegran, G. (1997) Ultrasound Doppler estimates of femoral artery blood flow during dynamic knee extensor exercise in humans. Journal of Applied Physiology, 83, 1383-1388.

[7] Osada, T. and Rådegran, G. (2002) Femoral artery inflow in relation to external and total work rate at different knee extensor contraction rates. Journal of Applied Physiology,
92, 1325-1330.

[8] Walløe, L. and Wesche, J. (1988) Time course and magnitude of blood flow changes in the human quadriceps muscles during and following rhythmic exercise. Journal of Physiology (London), 405, 257-273.

[9] Shoemaker, J.K., Hodge, L. and Hughson, R.L. (1994) Cardiorespiratory kinetics and femoral artery blood velocity during dynamic knee extension exercise. Journal of Applied Physiology, 77, 2625-2632.

[10] Andersen, P. and Saltin, B. (1985) Maximal perfusion of skeletal muscle in man. Journal of Physiology (London), 366, 233-249.

[11] Gill, R.W. (1985) Measurement of blood flow by ultrasound: Accuracy and sources of error. Ultrasound in Medicine and Biology, 11, 625-641. http://dx.doi.org/10.1016/0301-5629(85)90035-3

[12] Hughson, R.L., MacDonald, M.J., Shoemaker, J.K. and Borkhoff, C. (1997) Alveolar oxygen uptake and blood flow dynamics in knee extension ergometry. Methods of Information in Medicine, 36, 364-367.

[13] Osada, T. (2004) Muscle contraction-induced limb blood flow variability during dynamic knee extensor. Medicine and Science in Sports and Exercise, 36, 1149-1158. http://dx.doi.org/10.1249/01.MSS.0000132272.36832.6A

[14] Rådegran, G. and Saltin, B. (1998) Muscle blood flow at onset of dynamic exercise in humans. American Journal of Physiology Heart and Circulatory Physiology, 274, H314-H322.

[15] Robergs, R.A., Icenogle, M.V., Hudson, T.L. and Greene, E.R. (1997) Temporal inhomogeneity in brachial artery blood flow during forearm exercise. Medicine and Science in Sports and Exercise, 29, 1021-1027. http://dx.doi.org/10.1097/00005768-199708000-00006

[16] Isnard, R., Lechat, P., Kalotka, H., Chikr, H., Fitoussi, S., Salloum, J., Golmard, J-L., Thomas, D. and Komajda, M. (1996) Muscular blood flow response to submaximal leg exercise in normal subjects and in patients with heart failure. Journal of Applied Physiology, 81, 2571-2579.

[17] Leyk, D., Eßfeld, D., Baum, K. and Stegemann, J. (1992) Influence of calf muscle contractions on blood flow parameters measured in the arteria femoralis. International Journal of Sports Medicine, 13, 588-593. http://dx.doi.org/10.1055/s-2007-1024571

[18] MacDonald, M.J., Shoemaker, J.K., Tschakovsky, M.E. and Hughson, R.L. (1998) Alveolar oxygen uptake and femoral artery blood flow dynamics in upright and supine leg exercise in humans. Journal of Applied Physiology, 85, 1622-1628.

[19] Sjøgaard, G., Kiens, B., Jørgensen, K. and Saltin, B. (1986) Intramuscular pressure, EMG and blood flow during low-level prolonged static contraction in man. Acta Physiologica Scandinavica, 128, 475-484. http://dx.doi.org/10.1111/j.1748-1716.1986.tb08002.x

[20] Andersen, P., Adams, R.P., Sjøgaard, G., Thorboe, A. and Saltin, B. (1985) Dynamic knee extension as model for study of isolated exercising muscle in humans. Journal of Applied Physiology, 59, 1647-1653.

[21] Osada, T. and Rådegran, G. (2006) Differences in exer- 
cising limb blood flow variability between cardiac and muscle contraction cycle related analysis during dynamic knee extensor. Journal of Sports Medicine and Physical Fitness, 46, 590-597.

[22] Osada, T. and Rådegran, G. (2006) Alterations in the blood velocity profile influence the blood flow response during muscle contractions and relaxations. Journal of Physiological Science, 56, 195-203. http://dx.doi.org/10.2170/physiolsci.RP002905

[23] Cronestrand, R. (1970) Leg blood flow at rest and during exercise after reconstruction for occlusive disease. Scandinavian Journal of Thoracic Cardiovascular Surgery, Supplement 4, 1-24.

[24] Jorfeldt, L., Juhlin-Dannfelt, A., Pernow, B. and Wassén, E. (1978) Determination of human leg blood flow: A thermodilution technique based on femoral venous bolus injection. Clinical Science and Molecular Medicine, 54, 517-523.

[25] Lassen, N.A., Linbjerg, I. and Munck, O. (1964) Measurement of blood flow through skeletal muscle by intramuscular injection of xenon 133. Lancet, 1, 686-689. http://dx.doi.org/10.1016/S0140-6736(64)91518-1

[26] Rådegran, G., Pilegaard, H., Nielsen, J.J. and Bangsbo, J. (1998) Microdialysis ethanol removal reflects probe recovery rather than local blood flow in skeletal muscle. Journal of Applied Physiology, 85, 751-757.

[27] Boushel, R., Langberg, H., Olesen, J., Nowak, M., Simonsen, L., Bülow, J. and Kjær, M. (2000) Regional blood flow during exercise in humans measured by nearinfrared spectroscopy and indocyanine green. Journal of Applied Physiology, 89, 1868-1878.

[28] Ruotsalainen, U., Raitakari, M., Nuutila, P., Oikonen, V., Sipilä, H., Teräs, M., Knuuti, M.J., Bloomfield, P.M. and Iida, H. (1997) Quantitative blood flow measurement of skeletal muscle using oxygen-15-water and PET. Journal of Nuclear Medicine, 38, 314-319.

[29] Jensen, B.R., Sjøgaard, G., Bornmyr, S., Arborelius, M. and Jørgensen, K. (1995) Intramuscular laser-Doppler flowmetry in the supraspinatus muscle during isometric contractions. European Journal of Applied Physiology and Occupational Physiology, 71, 373-378. http://dx.doi.org/10.1007/BF00240420

[30] Rådegran, G. (1999) Limb and skeletal muscle blood flow measurements at rest and during exercise in human subjects. Proceedings of Nutrition Society, 58, 887-898. http://dx.doi.org/10.1017/S0029665199001196

[31] Tschakovsky, M.E., Saunders, N.R., Webb, K.A. and O'donnell, D.E. (2006) Muscle blood-flow dynamics at exercise onset: Do the limbs differ? Medicine and Science in Sports and Exercise, 38, 1811-1818. http://dx.doi.org/10.1249/01.mss.0000230341.86870.4f

[32] Osada, T. and Rådegran, G. (2009) Femoral artery blood flow and its relationship to spontaneous fluctuations in rhythmic thigh muscle workload. Clinical Physiology and Functional Imaging, 29, 277-292. http://dx.doi.org/10.1111/j.1475-097X.2009.00868.x 